\title{
Management and Prognostic Factors of Penetrating Craniocerebral Wounds at One Teaching Hospital in Benin
}

\author{
Olatoundji Holden Fatigba ${ }^{*}{ }^{(0)}$, Hamidath Bio Sika Yarou ${ }^{1}\left(\mathbb{D}\right.$, Kisito Quenum $^{1}$ (),

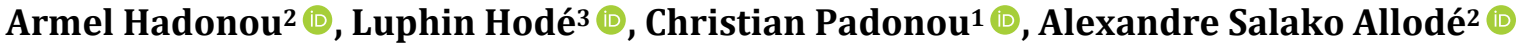 \\ ${ }^{1}$ Department of Neurosurgery, Medicine School of Parakou University, Borgou, Benin, Africa \\ ${ }^{2}$ Department General Surgery, Medicine School of Parakou University, Borgou, Benin, Africa \\ ${ }^{3}$ Department of Trauma and Orthopedic Surgery, Medicine School of Abomey-Calavi University, Benin, Africa \\ Email: `holfatigba@gmail.com, hamidathbiosika@gmail.com, kisitoq@gmail.com, padstevian@yahoo.fr, armelhad@gmail.com, \\ allodealexandre@yahoo.fr, luphin@gmail.com
}

\begin{abstract}
How to cite this paper: Fatigba, O.H., Yarou, H.B.S., Quenum, K., Hadonou, A., Hodé, L., Padonou, C. and Allodé, A.S. (2021) Management and Prognostic Factors of Penetrating Craniocerebral Wounds at One Teaching Hospital in Benin. Open Journal of Modern Neurosurgery, 11, 34-48.

https://doi.org/10.4236/ojmn.2021.111005
\end{abstract}

Received: November 20, 2020

Accepted: January 18, 2021

Published: January 21, 2021

Copyright $\odot 2021$ by author(s) and Scientific Research Publishing Inc. This work is licensed under the Creative Commons Attribution International License (CC BY 4.0).

http://creativecommons.org/licenses/by/4.0/

\begin{abstract}
Introduction. Penetrating craniocerebral wounds (PCCWs) are a particular lesion in the category of traumatic brain injury (TBI). The objective of this study was to describe the management of these lesions, and to identify signifiant risk factors associated with mortality in patients with a PCCW. Methods. It was a transversal, descriptive and analytical study performed in Departmental Teaching Hospital of Borgou and Alibori in Benin. From January 1, 2015 to June 30, 2020, patients with a PCCW were retained. Risk factors of mortality and morbidity associated to etiological, clinical and surgical parameters were assessed using the chi-square test. $\mathrm{p}$ value $<0.05$ was considered to be statistically significant. Results. During the study period, 1267 cases of traumatic brain injuries (TBI) were admitted. Of these patients, 77 (6.1\%) cases of PCCW were retained. These patients were divided into 66 (85.7\%) male and $11(14.3 \%)$ female. The mean age of the patients was $22.6 \pm 14.8$ years (range from 2 years to 70 years). The circumstances of occurrence were a traffic accident in $42(54.5 \%)$ cases, an assault in 33 cases $(42.9 \%)$ and a fall $2(2.6 \%)$. The PCCW was unilateral in 71 cases $(92.2 \%)$. A brain CT-scan was performed in $60(77.9 \%)$ patients. Surgery was performed in 69 (89.6\%) patients. Post-operative outcomes were simple in $59(85.5 \%)$ cases. GCS, pupillary abnormalities, motor deficit were a statistically significant risk factor associated with death or sequels $(\mathrm{p}<0.0001)$. Conclusion. The identification of risk factors of mortality or sequels is a major step for an efficient management of PCCWs and a reduction of morbidity and mortality. Whatever strategies are adopted, prevention must remain a priority.
\end{abstract}




\section{Keywords}

Traumatic Brain Injuries, Craniocerebral Wounds, Glasgow Coma Scale, Risk Factors, Mortality

\section{Introduction}

Penetrating craniocerebral wounds (PCCWs) are a particular lesions in the category of traumatic brain injury (TBI). They are defined as a continuity of all planes separating the brain parenchyma from the external environment [1] [2] [3]. It is a post-traumatic communication between the intracranial setting and the external ambient environment. The first anatomical descriptions presented by Cushing [4] and Gordon [5] already considered them to be exceptional lesions. Circumstances of occurrence are varied. The causes of these lesions, once considered as due to military or civil armed conflicts, have diversified with the development of road traffic, population growth and the events of societies [6]-[11]. The seriousness of these injuries depends on several factors, the most frequently cited of which include the GCS, their extension, the location, the associated intracerebral injuries and the management of these injuries [1] [12] [13]. The high morbidity and mortality and the almost certain risk of hemorrhage and infection have made PCCW an emergency diagnosis and treatment [14] [15] [16]. The immediate management of the patient is fundamental and must be specific to the hospital center. In Parakou, Benin, PCCWs have already been reported as part of the panorama of lesions observed in patients admitted for TBI [17]. The objective of this study was to report the frequency of these lesions at the CHUD-B/A in Parakou, to describe the management of these lesions, and to identify significant risk factors associated with mortality in patients with a PCCW.

\section{Patients and Methods}

It was a transversal, descriptive and analytical study. This study was performed in the neurosurgery service of the Departmental Teaching Hospital of Borgou and Alibori (CHDU-B/A). From January 1, 2015 to June 30, 2020, all patients hospitalized for a TBI were recorded. All patients with a penetrating cranioencephalic wound were retained whatever the cause and their age.

- Diagnostic Criteria

The diagnosis of head injury has been established in patients with TBI who had a combination:

- Scalp wound;

- Skull vault fracture;

- Wound of the dura mater associated with leakage of LCS with or without loss of brain tissue.

The brain CT-scan was the imaging exam considered. The variables studied 
were, age, sex, circumstances of trauma occurrence, clinical signs, imaging data, treatment modalities, postoperative course, sequelae and lethality. Information about these variables was obtained by examining patients' admission records and reviewing surgical suite registers.

Risk factors of mortality and morbidity associated to etiological, clinical and surgical parameters were assessed using the chi-square test. $\mathrm{p}$ value $<0.05$ was considered to be statistically significant. All statistical analyses were performed using Open Epi version 7.

\section{Results}

During the study period, 1267 cases of TBI were admitted. Of these patients, 77 (6.1\%) cases of PCCW were retained. These patients were divided into 66 (85.7\%) male and $11(14.3 \%)$ female. The mean age of the patients was $22.6 \pm$ 14.8 years (range from 2 years to 70 years). The circumstances of occurrence were a traffic accident in $42(54.5 \%)$ cases, an assault in 33 cases (42.9\%) and a fall $2(2.6 \%)$. In cases of assault, the traumatic agent was a machete, a firearm, a stick and nails in 21 (27.3\%), 5 (6.5\%), 4 (5.2\%) and 3 (3.9\%) cases respectively.

The mean time to admission was $36.5 \pm 72.7$ hours (range from 30 minutes to 15 days). This time was between 1 hour and 6 hours in 37 (48\%) cases, between 6 hours and 24 hours in $16(20.8 \%)$ cases, between 24 hours and 48 hours in 12 (15.6\%) cases and after 48 hours in $12(15.6 \%)$ cases.

At admission, 55 (71.4\%) patients had stable hemodynamic and respiratory status. Hemodynamic or respiratory instability was observed in $22(28.6 \%)$ cases. According to the Glasgow coma scale (GCS), patients were divided into severe TBI $(24.7 \% ; \mathrm{n}=19)$, moderate TBI $(20.8 \% ; \mathrm{n}=16)$ and mild TBI $(54.5 \% ; \mathrm{n}=$ 42). Clinical manifestations observed at admission were reported in Table 1.

The PCCW was unilateral in 71 cases $(92.2 \%)$ and bilateral in $6(7.8 \%)$. The distribution of the different locations of the PCCW was reported in Table 2. An illustration of these PCCWs is shown in Figure 1. An extracerebral lesion associated with the PCCW was observed in $26(33.8 \%)$ patients. A brain CT-scan was performed in $60(77.9 \%)$ patients. The mean time to perform a brain CT-scan was $16.2 \pm 9.7$ hours (range from one hour to 21 days). The distribution of lesions objectified in the brain CT-scan of patients was reported in Table 3. Figure 2 is an illustration of the appearance of these PCCWs as shown by the brain CT-scan.

Each patient on admission received antibiotic therapy consisting of a combination of Ceftriaxone/Metronidazole and a tetanus vaccination. An anticonvulsant treatment was instituted in 25 (32.5\%) patients. An operative indication was indicated for all patients. Of the 77 patients, 8 (10.4\%) died before admission to the operating room. Neurosurgical intervention was performed in $69(89.6 \%)$ patients. The mean time to admission to the operating room was $21 \pm 7$ hours (range from 12 hours to 14 days).

The surgical procedure consisted successively of five main steps (Figure 3): 
Table 1. Symptoms or signs seen during examination of penetrating craniocerebral wound patients.

\begin{tabular}{ccc}
\hline & Frequency & Percentage \\
\hline Agitation & 51 & 66.2 \\
Consciousness impairment & 49 & 63.6 \\
CSF leak & 34 & 44.1 \\
Skull vault deformation & 24 & 5.1 \\
Epistaxis & 23 & 29.8 \\
Otorrhagia & 18 & 23.4 \\
Brain tissue leak & 17 & 22.1 \\
Motor deficit & 13 & 17.8 \\
Pupillarity abnormalities & 11 & 15.1 \\
\hline
\end{tabular}

${ }^{*}$ CSF: Cerebrospinal fluid.

Table 2. Localizations of penetrating craniocerebral wound observed in patients.

\begin{tabular}{ccc}
\hline Localization & Effectifs & Pourcentage \\
\hline Frontal & 25 & 32.5 \\
Parietal & 6 & 7.8 \\
Temporal & 6 & 7.8 \\
Occipital & 8 & 10.4 \\
Fronto-parietal & 10 & 13 \\
Biparietal & 4 & 5.2 \\
Fronto-temporal & 6 & 7.8 \\
Parieto-occipital & 4 & 5.2 \\
Frontoparietotemporal & 8 & 10.4 \\
\hline
\end{tabular}

Table 3. Distribution of injuries visualized on brain CT-scans of patients managed for a penetrating craniocerebral wound.

\begin{tabular}{ccc}
\hline & Frequency & Percentage \\
\hline Depressed fracture & 39 & 65 \\
Brain contusion & 27 & 45 \\
Intracranial bone fragments & 10 & 16.7 \\
Shot impact & 5 & 8.3 \\
Epidural hematoma & 5 & 8.3 \\
Subdural hematoma & 4 & 6.7 \\
subarachnoid hemorrhage & 4 & 6.7 \\
Encephalitis & 4 & 6.7 \\
Pneumocephalus & 4 & 6.7 \\
Cerebral ischemia & 2 & 3.3 \\
\hline
\end{tabular}




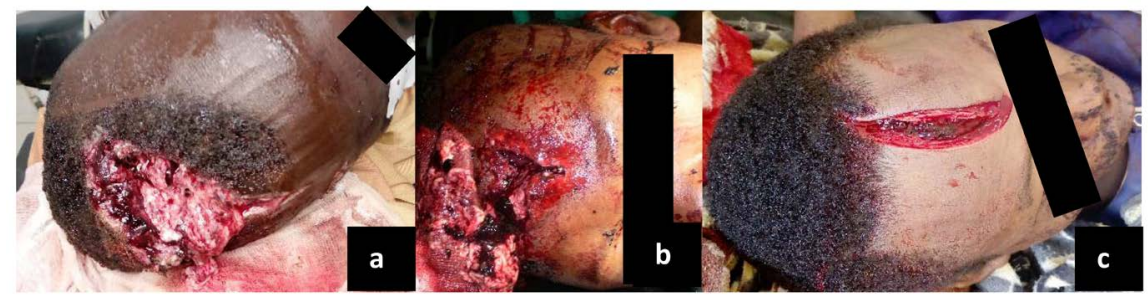

Figure 1. Macroscopic view of penetrating craniocerebral wound at patients' admission. (a) parietal degrading wound with loss of brain tissue caused by traffic accident (b) frontal localization (c) frontal PCCW caused by machete assault.

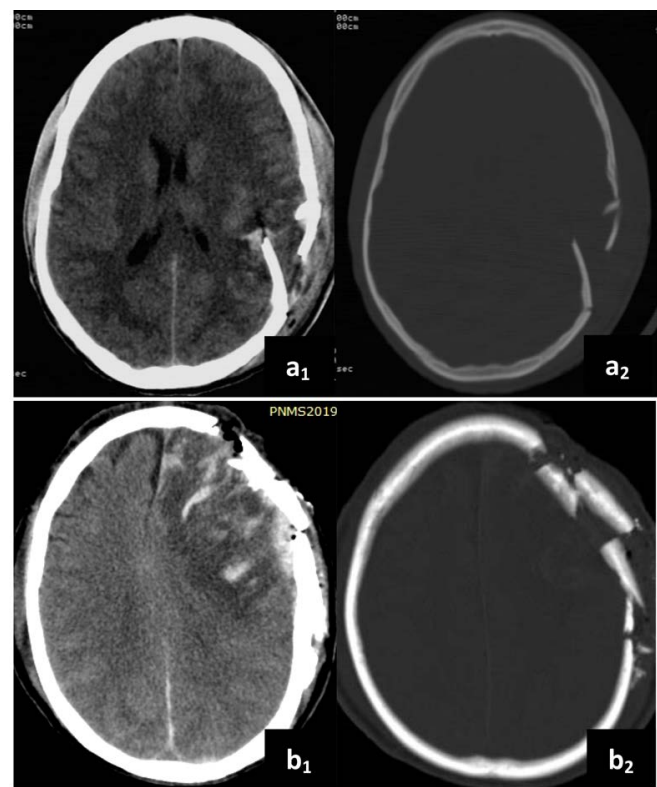

Figure 2. CT view of PCCW. (a) Left parietal PCCW in parenchymal $\left(\mathrm{a}_{1}\right)$ and bony $\left(a_{2}\right)$ views $(b)$ Frontoparietal PCCW left in a parenchymal $\left(b_{1}\right)$ and bony $\left(b_{2}\right)$ views associated with a brain contusion and with multiple bone fragments.

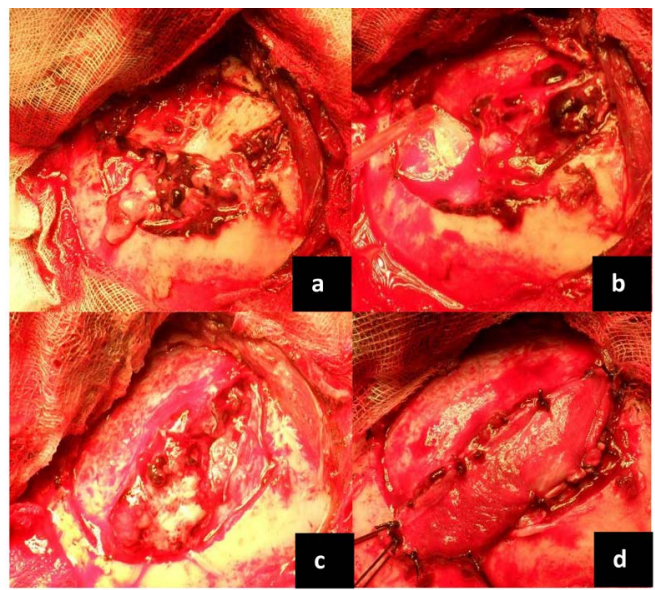

Figure 3. Surgical procedure to repair a PCCW. (a) Exposure of lesions after skin time. There is an outcome of cerebral material, fracture and embedding of bone fragments in the cerebral parenchyma. (b) Lavage phase, removal of necrotic cerebral tissue. (c) Exposure of the dura mater tear and exposure of borders. (d) Tight closure of the brain wound with pericranium followed by suspension of the dura mater. 
1) Careful and abundant washing of the lesion site with saline to allow debridement and exposure of the lesions.

2) Careful removal of contused or mortified brain tissue.

3) Identification and extraction of intracranial fragments (esquillectomy) or straightening of the bony edges embedded in the cerebral parenchyma.

4) Systematic search and identification of the edges of the dura mater.

5) Systematic repair of dura mater wounds performed for all patients. It consisted of an anatomical reconstitution using a tight closure performed with pericranium or temporal fascia.

Post-operative outcomes were simple in $59(85.5 \%)$ cases. Post-operative complications were observed in $8(11.6 \%)$ patients. These were $3(4.3 \%)$ cases of sepsis, $2(2.9 \%)$ cases of meningitis, $2(2.9 \%)$ cases of seizures and $1(1.5 \%)$ case of brain abscess. Post-operative mortality was $7.8 \%(n=6)$. There were 2 deaths in the immediate postoperative period and 4 deaths among patients with postoperative complications. The overall pre- and postoperative mortality was $18.2 \%$ $(\mathrm{n}=14)$. Among the 63 surviving patients, complete recovery was observed in 51 (81\%) patients and definitive sequelae were observed in $12(19 \%)$ patients. These sequelae were divided into neurological deficits, neuropsychic disorders, aphasia and bilateral visual loss in 58.4\% $(\mathrm{n}=7), 25 \%(\mathrm{n}=3), 8.3 \%(\mathrm{n}=1)$ and $8.3 \%(\mathrm{n}$ $=1$ ) respectively. Severity of consciousness disorders was a statistically significant risk factor of cause of death $(\mathrm{p}<0.0001)$. The mortality risk factors assessed were reported in Table 4 . The presence of motor deficit at patient admission was a statistically significant risk factor of sequelae $(\mathrm{p}<0.0001)$. The risk factors for the occurrence of the sequelae studied were reported in Table 5.

The average duration of patient hospitalization was $19 \pm 17.4$ days (Range from 1 day to 90 days). The mortality and morbidity risk factors sought and their significance level were reported in a recapitulative table (Table 6).

The main risk factors that were significantly associated with mortality or sequelae $(\mathrm{p}<0.05)$ were pupillary abnormalities, GCS, motor deficit and PCCW localization.

\section{Discussion}

Several studies concerning TBI have been performed in Parakou, Benin [17] [18]. These studies had already mentioned PCCW as part of the lesions observed in patients. By conducting a study focusing on PCCW, the authors were able to assess the problem of these lesions at Parakou. Statistical tests were used to evaluate the risk factors associated with the patients' outcomes. This study now offers quantitative and qualitative indicators necessary to manage PCCW in neurosurgical practice in Benin and during prevention campaigns. The main restriction of this study was the impossibility for the authors to explore all potential risk factors. This limitation was due to the adequacy of the technical platform, in particular the under-equipment of our intensive care unit.

\section{- Frequency}


Table 4. Risk factors of mortality assessed in patients managed for a penetrating cranioencephalic wound.

\begin{tabular}{|c|c|c|c|c|}
\hline & Frequency & Mortality n(\%) & $X^{2}$ & $p$ \\
\hline \multicolumn{5}{|l|}{ Aetiologies } \\
\hline Traffic accident & 42 & $8(19)$ & 0.46 & 0.79 \\
\hline Assault & 33 & $6(18.2)$ & & \\
\hline Falls & 2 & 0 & & \\
\hline \multicolumn{5}{|l|}{ GCS } \\
\hline Mild & 42 & $2(4.7)$ & 20.59 & 0.0001 \\
\hline Moderate & 16 & $2(12.5)$ & & \\
\hline severe & 19 & $10(52.6)$ & & \\
\hline \multicolumn{5}{|l|}{ Pupillary abnormalities } \\
\hline Present & 11 & 6 & 8.73 & 0.003 \\
\hline Absent & 66 & 8 & & \\
\hline \multicolumn{5}{|l|}{ Motor deficit } \\
\hline Present & 13 & 8 & 16.41 & 0.0001 \\
\hline Absent & 64 & 6 & & \\
\hline \multicolumn{5}{|l|}{ Localization } \\
\hline Frontal & 25 & $4(16)$ & 18.56 & 0.029 \\
\hline Parietal & 6 & $2(33.3)$ & & \\
\hline Temporal & 6 & 0 & & \\
\hline Occipital & 8 & 0 & & \\
\hline Fronto-parietal & 10 & $4(40)$ & & \\
\hline Biparietal & 4 & $2(50)$ & & \\
\hline Fronto-temporal & 6 & 0 & & \\
\hline Parieto-occipital & 4 & 0 & & \\
\hline Frontoparietotemporal & 8 & $2(25)$ & & \\
\hline \multicolumn{5}{|l|}{ Associated lesions * } \\
\hline Present & 23 & $6(26.1)$ & 0.72 & 0.19 \\
\hline Absent & 54 & $8(14.8)$ & & \\
\hline \multicolumn{5}{|l|}{ Surgery } \\
\hline Yes & 69 & $6(8.7)$ & 34.27 & 0.0001 \\
\hline No & 8 & $8(100)$ & & \\
\hline
\end{tabular}

${ }^{\star}$ Extracerebral lesions. 
Table 5. Risk factors of sequels assessed in patients managed for a penetrating cranioencephalic wound.

\begin{tabular}{|c|c|c|c|c|}
\hline & Frequency & Sequels $\mathrm{n}(\%)$ & $X^{2}$ & $p$ \\
\hline \multicolumn{5}{|l|}{ Aetiologies } \\
\hline Traffic accident & 42 & $6(14.3)$ & 0.34 & 0.84 \\
\hline Assault & 33 & $6(17.6)$ & & \\
\hline Falls & 2 & 0 & & \\
\hline \multicolumn{5}{|l|}{ GCS } \\
\hline Mild & 42 & $4(9.5)$ & 14.28 & 0.0007 \\
\hline Moderate & 16 & 0 & & \\
\hline severe & 19 & $8(42.1)$ & & \\
\hline \multicolumn{5}{|l|}{ Pupillary abnormalities } \\
\hline Present & 11 & $6(54.5)$ & 11.55 & 0.001 \\
\hline Absent & 66 & $6(9.1)$ & & \\
\hline \multicolumn{5}{|l|}{ Motor deficit } \\
\hline Present & 13 & $8(61.5)$ & 21.08 & 0.0001 \\
\hline Absent & 64 & $4(6.25)$ & & \\
\hline \multicolumn{5}{|l|}{ Localization } \\
\hline Frontal & 25 & 0 & 22.52 & 0.007 \\
\hline Parietal & 6 & $2(33.3)$ & & \\
\hline Temporal & 6 & $2(33.3)$ & & \\
\hline Occipital & 8 & 0 & & \\
\hline Fronto-parietal & 10 & $2(20)$ & & \\
\hline Biparietal & 4 & 0 & & \\
\hline Fronto-temporal & 6 & 0 & & \\
\hline Parieto-occipital & 4 & $2(50)$ & & \\
\hline Frontoparietotemporal & 8 & $4(50)$ & & \\
\hline \multicolumn{5}{|l|}{ Associated lesions * } \\
\hline Present & 23 & $2(8.7)$ & 0.55 & 0.23 \\
\hline Absent & 54 & $10(18.5)$ & & \\
\hline \multicolumn{5}{|l|}{ Surgery } \\
\hline Yes & 69 & 12 & 0.59 & 0.23 \\
\hline No & 8 & 0 & & \\
\hline
\end{tabular}

*Extracerebral lesions. 
Table 6. Recapitulative table of risk factors of mortality and sequels associated with penetrating cranioencephalic wounds and their levels of significance.

\begin{tabular}{ccccc}
\hline & \multicolumn{2}{c}{ Sequels } & \multicolumn{2}{c}{ Mortality } \\
\cline { 2 - 5 } & $X^{2}$ & $p$ & $X^{2}$ & $p$ \\
\hline Aetiology & 0.34 & 0.84 & 0.24 & 0.88 \\
GCS & 14.28 & 0.0007 & 20.59 & 0.0001 \\
Pupillary abnormalities & 11.55 & 0.001 & 8.73 & 0.003 \\
Motor deficit & 21.08 & 0.0001 & 16.41 & 0.0001 \\
Localization & 22.52 & 0.007 & 18.56 & 0.029 \\
Associated lesions* & 0.55 & 0.23 & 0.72 & 0.19 \\
Surgery & 0.59 & 0.23 & 34.27 & 0.0001 \\
\hline
\end{tabular}

*Extracerebral Lesions.

The frequency of PCCWs was $6.1 \%$. This frequency varied by study. Thiam et al. [19] in Dakar reported 4\%. Other authors such as Sanoussi et al. [20] and Rabiou et al. [21] in Niger and Doleagbenou et al. [22] in Togo reported frequencies of $2.9 \%, 8.5 \%$ and $10.5 \%$ respectively. Lower frequencies of $0.4 \%$ were reported by Rasolonjatovo et al. [10] in Madagascar. All these authors observed a clear male predominance. The same observation was made in our study. Male predominance is constant in head and brain injuries whatever the mechanism or cause [8] [14] [23] [24]. According to these authors, PCCW is a public health problem in their respective countries.

\section{- Aetiologies}

In the African series, road accidents and assaults (brawls, violent robberies, popular vindictiveness) are the main causes of PCCW [10] [19] [20] [21] [22] [25]. These road accidents were the first cause of PCCW in our study (54.5\%) as observed by other authors [20] [22]. According to Thiam et al. [19], assaults were the primary cause (41\%). This frequency of aggression was similar to that observed in our study (42.9\%) although aggression was the second cause in our study. As reported by Thiam et al. [19] in Senegal, aggression was the primary cause of PCCW in Madagascar [10]. A particular type of aggression was observed in our study; it was the use of nails as a method of aggression. These particular types of PCCW were the subject of research and reported in an article published in 2020 [26]. These different observed causes of PCCW make these injuries preventable. These causes reported in underdeveloped countries are in opposition to the causes of PCCW observed in occidental countries. In these countries, ballistic trauma was the most reported cause. The circumstances were accidental, due to a suicide attempt or in the context of armed conflict [6] [7] [8] [13] [16] [27]. In cases of suicide or patients with a psychiatric history, the weapon used was a gunshot or nail guns. [11] [28] [29] [30].

Location

The location of PCCWs varied from study to study independently of the circumstances in which they occurred [23] [25] [31] [32]. However, the main loca- 
tions were frontal [13] [19] [33], parietal [9] [25] or frontaloparieto-temporal [7]. The position of the victims at the time of contact and the virulence of the aggression seem to be determining factors in the predominance of localizations. Independent of the location of a PCCW, the management of lesions follows the same principles.

\section{- Imaging}

Although the diagnosis of PCCW is visual, medical imaging is still necessary [1] [30] [34]. Brain CT was the most commonly used imaging test in our study (77.9\%). It is the examination of choice that allows a comprehensive evaluation of the lesions according to the traumatic agent involved. It also provides information on the associated intracerebral lesions and the lesion trajectory [32] [35] [36]. Angiography is justified if a vascular lesion is suspected [1] [15] [30]. Although little or not recommended in the published literature, standard radiography retains indications and contributes to the identification of metallic objects [10] [37] [38]. This imaging examination is still widely used in under-medical healthcare centers [9] [25] [26] [39].

\section{- Treatment}

The management of PCCW is a neurosurgical emergency [1] [31] [40]. This treatment is based on two mainstays: surgery and antibiotic therapy [7] [30] [41]. The condition of patients on admission may require a stay in the intensive care unit and stabilization of their hemodynamic or respiratory status prior to admission to the operating room [14] [28] [42]. The surgical principles are debridement, exposure of lesions, abundant saline lavage, removal of foreign bodies, especially cranial fragments, removal of mortified brain tissue, and tight closure of the dura mater with pericranium or temporal fascia [43]. Cranioplasty is sometimes necessary to complete the management of this disease [1] [10]. The obsession with the management of cranioplasty is the occurrence of infection or leakage of CSF [43]. In all studies, antibiotic therapy was used routinely. Antibiotic therapy should be initiated on admission [25] [40] [41]. Antibiotic therapy is the best barrier to pre- or post-operative infection, which can be a cause of mortality [9] [44]. In our study our attitude was identical to that reported in the publications literature.

\section{- Mortality and prognostic factors}

Complete recovery was observed in $51(81 \%)$ patients undergoing surgery and definitive sequelae were observed in 12 (19\%) patients. The overall mortality was $18.2 \%$. Mortality was $7.8 \%$ among patients who underwent surgery. Mortality due to PCCW varies from study to study independently of etiology [14] [23] [31] [42]. According to Rich et al. [16], Thiam et al. [19], Gönül et al. [43] it was 5\%, $8 \%$ and $8 \%$ respectively. Higher lethalities have been reported by authors such as Izci et al. [30] reporting a $41 \%$ mortality in cases of suicide. Risk factors that may induce or influence mortality due to PCCW have been the subject of several studies [6] [8] [12] [29] [43] [45]. These included GCS at admission, pupillary status or reactivity, infection, the presence of subarachnoid hemorrhage and to some degree, the existence of motor deficit. [7] [16] [45] [46]. In our study, GCS 
$<8$ (severe TBI), preoperative pupillary abnormalities and the presence of motor deficit were significantly associated with mortality $(\mathrm{p}<0.0001)$. The implication of these same parameters in the deaths of patients managed of PCCW has been reported by Levy et al. [45]. Our results confirm the observations of many authors [1] [12] [16] [24] [42]. The implication of all studies of GCS in deaths led Rish et al. [16] as well as Levy et al. [45] or Lieberman et al. [46] to say that any patient admitted for PCCW with a GCS $\leq 5$ had no reasonable chance of survival and should abstain from any surgical procedure. According to these three authors, including Bodanapally et al. [15] the presence of SA hemorrhage was to be considered a significant factor associated with mortality. In addition to these clinical and therapeutic risk factors, which involved all causes of PCCW without distinction, there are also parameters that are sometimes specific to intracerebral gunshot PCCW. According to Paradot et al. [27], these are the trajectory of the projectile and its passage from the median line. These prognostic factors evoked by other authors [2] [28] have not been explored in our study. Extracerebral parameters can also impact mortality. These are age, suicide attempt, mode of trauma, low blood pressure, coagulopathy and respiratory distress [1] [2] [13] [16] [28]. Our working conditions did not allow us to explore these parameters. Among the patients who survived with sequelae, the location of PCCW was a significant risk factor $(\mathrm{p}<0.0003)$ as were GCS, pupillary abnormalities and the presence of motor deficit. These parameters should be considered in the management of PCCW cases.

\section{Conclusion}

PCCWs are serious traumatic brain injuries. The identification of risk factors of mortality or sequelae is a major step for an efficient management of PCCWs and a reduction of morbidity and mortality. The management of PCCWs, depending on the severity of the injury, can require the involvement of several actors at the same time. The protocols for the management of the injuries may be nuanced according to the etiology. These aetiologies can have an influence on patient prognosis. Whatever strategies are adopted, prevention must remain a priority.

\section{Ethical Considerations}

The authors of this research article have no ethical conflicts to disclose. Local Ethical Committee for Biomedical Research of the University of Parakou (CLERB-UP) confirmed our study.

\section{Conflicts of Interest}

The authors declare no conflicts of interest regarding the publication of this paper.

\section{References}

[1] Kazim, S.F., Shamim, M.S., Tahir, M.Z., Enam, S.A. and Waheed, S. (2011) Man- 
agement of Penetrating Brain Injury. Journal of Emergencies, Trauma, and Shock, 4, 395-402. https://doi.org/10.4103/0974-2700.83871

[2] Fornes, P., Hauw, J. and Lecomte, D. (1994) Neuropathological Examination of Gunshot Wounds of the Brain. Journal de Médecine Légale Droit Médical, 37, 257-262.

[3] Anonymous (2001) Guidelines for the Management of Penetrating Brain Injury. Introduction and Methodology. Journal of Trauma, 51, S3-S6

[4] Cushing, H. (1918) Notes on Penetrating Wounds of the Brain. British Medical Journal, 1, 221-226. https://doi.org/10.1136/bmj.1.2982.221

[5] Gordon, D.S. (1988) Penetrating Head Injuries. The Ulster Medical Journal, 57, $1-10$

[6] Byrnes, D.P., Crockard, H.A., Gordon, D.S. and Gleadhill, C.A. (1974) Penetrating Craniocerebral Missile Injuries in the Civil Disturbances in Northern Ireland. British Journal of Surgery, 61, 169-176. https://doi.org/10.1002/bjs.1800610302

[7] Hammon, W.M. (1971) Analysis of 2187 Consecutive Penetrating Wounds of the Brain from Vietnam. Journal of Neurosurgery, 34, 127-131. https://doi.org/10.3171/jns.1971.34.2part1.0127

[8] Martínez-Bustamante, D., Pérez-Cárdenas, S., Ortiz-Nieto, J.M., Toledo-Toledo, R. and Martínez-Ponce de León, Á.R. (2015) Craniocerebral Gunshot Wounds in Civilian Population: Analysis of Experience in a Single Centre in Monterrey, México. Cirugía y Cirujanos (English Edition), 83, 94-99.

https://doi.org/10.1016/j.circen.2015.08.003

[9] Mathew, P., Nott, D.M. and Gentleman, D. (2016) Safe Management of Paediatric Penetrating Head Injury without Act Scanner: A Strategy for Humanitarian Surgeons Based on Experience in Southern Afghanistan. The Annals of The Royal College of Surgeons of England, 98, 198-205. https://doi.org/10.1308/rcsann.2016.0058

[10] Rasolonjatovo, E.C., Tsiaremby, M.G., Rakotondraibe, W.F., Ratovondrainy, W, Rabarijaona, M. and Andriamamonjy, C. (2016) Management of Craniocerebral Wounds at the CHU Joseph Ravoahangy Andrianavalona, Antananarivo-Madagascar. Revue D’Anesthésie-Réanimation, Médecine D’Urgence Et Toxicologie, 8, 4-7. http://www.rarmu.org/

[11] Alvis-Miranda, H.R., Rubiano, A.M., Agrawal, A., Rojas, A., Moscote-Salazar, L.R., Satyarthee, G.D., Calderon-Miranda, W.G., Hernandez, N.E. and Zabaleta-Churio, N. (2016) Craniocerebral Gunshot Injuries: A Review of the Current Literature. Bulletin of Emergency and Trauma, 4, 65-74.

[12] Emami, P., Czorlich, P., Fritzsche, F.S., Westphal, M., Rueger, J.M., Lefering, R. and Hoffmann, M. (2017) Impact of Glasgow Coma Scale Score and Pupil Parameters on Mortality Rate and Outcome in Pediatric and Adult Severe Traumatic Brain Injury: A Retrospective, Multicenter Cohort Study. Journal of Neurosurgery, 126, 760-767. https://doi.org/10.3171/2016.1.JNS152385

[13] Santiago, L.A., Bryan, C.O.H., Pramod, K., Dash, P.K., Holcomb, J.B., Wade, C.E. (2012) A Clinical Comparison of Penetrating and Blunt Traumatic Brain Injuries. Brain Injury, 26, 107-125. https://doi.org/10.3109/02699052.2011.635363

[14] Wang, T.B., Wang, Y.H., Xu, T.M., Li, L.B., Huo, M.L., Li, X., He, Y.D., Lin, Q.S., Mei, B.S., Zhou, X.H. and Jiang, B.G. (2020) Epidemiological and Clinical Characteristics of 3327 Cases of Traffic Trauma Deaths in Beijing from 2008 to 2017: A Retrospective Analysis. Medicine, 99, e18567.

https://doi.org/10.1097/MD.0000000000018567 
[15] Bodanapally, U.K., Krejza, J., Saksobhavivat, N., Jaffray, P.M., Sliker, C.W., Miller, L.A., Shanmuganathan, K. and Dreizin, D. (2014) Predicting Arterial Injuries after Penetrating Brain Trauma Based on Scoring Signs from Emergency CT Studies. The Neuroradiology Journal, 27, 138-145. https://doi.org/10.15274/NRJ-2014-10024

[16] Rish, B.L., Dillon, J.D. and Weiss, G.H. (1983) Mortality Following Penetrating Craniocerebral Injuries: An Analysis of the Deaths in the Vietnam Head Injury Registry Population. Journal of Neurosurgery, 59, 775-780.

https://doi.org/10.3171/jns.1983.59.5.0775

[17] Fatigba, O.H. and Padonou, J. (2010) Epidemiology of Traumatic Brain Injries in Parakou, Benin. Journal of the Neurological Sciences, 29, 25-33.

[18] Fatigba, O.H., Savi de Tove, K.M., Tchaou, A.B., Mensah, E., Allode, S.A. and Padonou, J. (2013) Surgical Management of Head Trauma: Problems, Results, and Perspectives at the Departmental Teaching Hospital of Borgou, Benin. World Neurosurgery, 80, 246-250. https://doi.org/10.1016/j.wneu.2011.09.016

[19] Thiam, A.B., Mudekereza, P.S., Ndoye, N., Tine, I., Ba, M.C., Sylla, F., Moumouni, A.K., Sayarh, M., Traore, C. and Badiane, S.B. (2013) Craniocerebral Wounds: Anatomical-Clinical Aspects about 39 Cases. Journal de Neurochirurgie, 18, 33-41

[20] Sanoussi, S., Abass, B.A., Baoua, M., Chaibou, M.S. and Rabiou, M.S. (2009) Epidemiological Clinical Therapeutic Aspects of Traumatic Brain Injuries at the National Hospital of Niamey in Niger. Revue Internationale de Sciences Médicale, 11, 27-32.

[21] Rabiou, M.S., Adamou, H., Habou, O., Amadou, M.I., Magagi, A., Maazou, H. and Adakal, O. (2016) Head Brain Injuries at the Zinder National Hospital: Retrospective Study about 153 Cases. Annales de l'Université Abdou Moumouni de Niamey, 11, 143-151.

[22] Doléagbénou, A.K., Ahanogbé, H.K., Kpélao, E., Békéti, K.A. and Egu, K. (2019) Epidemiological Aspects and Surgical Management of Traumatic Brain Injury in Adults at Sylvanus Olympio University Teaching Hospital of Lomé. Health Sciences Diseases, 20, 74-78.

[23] Dijkink, S., Krijnen, P., Hage, A., Van der Wilden, G.M., Kasotakis, G., den Hartog, D., Salim, A., Goslings, J.C., Bloemers, F.W., Rhemrev, S.J., King, D.R., Velmahos, G.C. and Schipper, I.B. (2018) Differences in Characteristics and Outcome of Patients with Penetrating Injuries in the USA and the Netherlands: A Multi-institutional Comparison. World Journal of Surgery, 42, 3608-3615. https://doi.org/10.1007/s00268-018-4669-8

[24] Wuthisuthimethawee, P., Lindquist, S.J., Sandler, N., Clavisi, O., Korin, T., Watters, D. and Gruen, R.L. (2015) Wound Management in Disaster Settings. World Journal of Surgery, 39, 842-853. https://doi.org/10.1007/s00268-014-2663-3

[25] Diop, A., Tine, I. and Hope, L. (2011) Cranio-Encephalic Wounds: Epidemiological, Clinical and Therapeutic Aspects in Dakar (Senegal). African Journal of Neurological Sciences, 30, 1-10.

[26] Fatigba, O.H, Hode, L. and Padonou, C. (2020) Intentional Penetrating Craniocerebral Injury Caused by a Nail: Clinical Presentation and Management of Three Cases. Open Journal of Modern Neurosurgery, 10, 458-463. https://doi.org/10.4236/ojmn.2020.104046

[27] Paradot, G., Aghakani, N., Montpellier, D., Parker, F. and Tadié, M. (2008) Craniocerebral Gunshot Wounds: A Study of Outcome Predictors. Neurochirurgie, 54, 79-83. https://doi.org/10.1016/j.neuchi.2007.11.002

[28] Jourdan, C., Rich, H., Brancel

[29] , B., Pialat, J., Grau, A. and Deleuz, R. (1987) Study of the Morbidity and Mortality 
of Suicidal Craniocerebral Gunshot Wounds from 41 Cases, Clinical and Médico-Legal Aspect. Journal Médecine légale et droit de la Santé, 30, 9-20.

[30] Erdogan, E., Gonul, E. and Seber, N. (2002) Craniocerebral Gunshot Wounds. Neurosurgery Quaterly, 12, 1-18.

https://doi.org/10.1097/00013414-200203000-00001

[31] Izci, Y., Kayali, H., Daneyemez, M., Koksel, T. and Cerrahoglu, K. (2003) The Clinical, Radiological and Surgical Characteristics of Supratentorial Penetrating Craniocerebral Injuries: A Retrospective Clinical Study. Tohoku Journal of Experimental Medicine, 201, 39-46. https://doi.org/10.1620/tjem.201.39

[32] Young, M., Putty, M., Finneran, M.M., Johnson, R., Keith Schaible, K. and Farhat, H. (2020) Multidisciplinary Management of Low-Velocity Nonmissile Penetrating Head Injuries. Cureus, 12, e7388. https://doi.org/10.7759/cureus.7388

[33] Marshall, L.F., Marshall, S.B., Klauber, M.R., Clark, M.B., Eisenberg, H.M., Jane, J.A., Luerssen, T.G., Marmarou, A. and Foulkers, M.A. (1991) A New Classification of Head Injury Based on Computerized Tomography. Journal of Neurosurgery, 75, S14-S20. https://doi.org/10.3171/sup.1991.75.1s.0s14

[34] Gulati, A., Srinivasan, B., Hunter, R. and Flood, T.R. (2010) Penetrating Knife Injury to the Frontal Lobe-A Case Report. Annals of the Royal College of Surgeons of England, 92, e41-e42. https://doi.org/10.1308/147870810X12699662981672

[35] Offiah, C.S. and Twigg, S. (2009) Imaging Assessment of Penetrating Craniocerebral and Spinal Trauma. Clinical Radiology, 64, 1146-1157.

https://doi.org/10.1016/j.crad.2009.06.004

[36] Rosenwasser, R.H., Andrews, D.W. and Jimenez, D.F. (1991) Penetrating craniocerebral Trauma. Surgical Clinics of North America, 71, 305-316. https://doi.org/10.1016/S0039-6109(16)45381-8

[37] Elserry, T., Anwer, H. and Esene, I.N. (2013) Image Guided Surgery in the Management of Craniocerebral Gunshot Injuries. Surgical Neurology International, 4, S448-S454. https://doi.org/10.4103/2152-7806.121642

[38] Kim, P.E., Go, J.L. and Zee, C.S. (2002) Radiographic Assessment of Cranial Gunshot Wounds. Neuroimaging Clinics of North America, 12, 229-248. https://doi.org/10.1016/S1052-5149(02)00007-2

[39] Gutiérrez-González, R., Boto, G., Rivero-Garvía, M., Pérez-Zamarrón, A. and Gómez, G. (2008) Penetrating Brain Injury by Drill Bit. Clinical Neurology and Neurosurgery, 110, 207-210. https://doi.org/10.1016/j.clineuro.2007.09.014

[40] Wani, A.A., Ramzan, A.U., Dar, T.I., Malik, N.K., Khan, A.Q., Wani, M.A., Alam, S. and Nizami, F.A. (2012) Management Dilemma in Penetrating Head Injuries in Comatose Patients: Scenario in Underdeveloped Countries. Surgical Neurology International, 3, 89.

[41] Alvis-Miranda, H.R., Villafañe, R.A., Rojas AGabriel Alcala-Cerra, A. and Moscote-Salazar, L.R. (2015) Management of Craniocerebral Gunshot Injuries: A Review. Korean Journal of Neurotrauma, 11, 35-43. https://doi.org/10.13004/kjnt.2015.11.2.35

[42] Bayston, R., de Louvois, J., Brown, E.M., Johnson, R.A., Lees, P. and Pople, I.K. (2000) Use of Antibiotics in Penetrating Craniocerebral Injuries. Infection in Neurosurgery Working Party of British Society for Antimicrobial Chemotherapy. Lancet, 355, 1813-1817. https://doi.org/10.1016/S0140-6736(00)02275-3

[43] Byun, C.S., Park, I.H., Oh, J.H., Bae, K.S., Lee, K.H. and Lee, E. (2015) Epidemiology of Trauma Patients and Analysis of 268 Mortality Cases: Trends of a Single Center in Korea. Yonsei Medical Journal, 56, 220-226. 
https://doi.org/10.3349/ymj.2015.56.1.220

[44] Gönül E., Baysefer. A., Kahraman, S., Ciklatekerlioğlu, O, Gezen, F, Yayla, O. and Seber, N. (1997) Causes of Infections and Management Results in Penetrating Craniocerebral Injuries. Neurosurgical Review, 20, 177-181.

https://doi.org/10.1007/BF01105561

[45] Rish, B., Caveness, W., Dillon, J., Kistler, J., Mohr, J. and Weiss, G. (1981) Analysis of Brain Abscess after Penetrating Craniocerebral Injuries in Vietnam. Neurosurgery, 9, 535-541. https://doi.org/10.1227/00006123-198111000-00008

[46] Levy, M.L., Masri, L.S., Lavine, S. and Apuzzo, M.L.J. (1994) Outcome Prediction after Penetrating Crânio-Cerebral Injury in a Civilian Population: Aggressive Surgical Management in Patients with Admission Glasgow Coma Scale of 3, 4 or 5. Neurosurgery, 35, 77-85. https://doi.org/10.1227/00006123-199407000-00012

[47] Lieberman, J.D., Pasquale, M.D., Garcia, R., Cipolle, M.D., Li, P.M, Thomas, E. and Wasser, T.E. (2003) Use of Admission Glasgow Coma Score, Pupil Size, and Pupil Reactivity to Determine Outcome for Trauma Patients. The Journal of Trauma: Injury, Infection, and Critical Care, 55, 437-443.

https://doi.org/10.1097/01.TA.0000081882.79587.17 